\title{
ISO 50001 based integrated energy management system and organization performance
}

\author{
Mustafa Yücel ${ }^{1,}{ }^{*}$, Muhsin Halis ${ }^{2}$ \\ 1, 2 Kastamonu University, Kastamonu, Turkey
}

\section{Index Terms}

Energy Management System ISO 50001

Organization Performance

Energy Saving

Received: 7 May 2016

Accepted: 25 May 2015

Published: 26 April 2016

\begin{abstract}
ISO 50001 is a systematic approach that puts forth some principles and requirements to establish a standard energy management system to increase energy performance by efficient use of energy. However, it is a guide to form objectives and tasks, which doesn't include specific measurements for evaluating energy performance. Hence, additional energy maturity models are required to evaluate the progress of the businesses in energy performance. In this study, the adaptation process of the ISO 50001 will be explained, and how a business can achieve better organizational performance by applying the energy management models that will be integrated into the ISO 50001 will be examined. With the assumption that ISO 50001 and additional energy management models cover each other and cannot be considered separately, the purpose of this study is to find out whether the businesses can obtain optimum performance while saving energy. In the scope of this purpose, applying an integrated energy management system based on ISO 50001 is assumed as more effective than implementing ISO 50001 by merely following its guidance since the organization can measure its performance level more accurately. At the end of the research, the effect of the energy management system will be clarified on organization performance.
\end{abstract}

(c) 2016 The Author(s). Published by TAF Publishing.

\section{INTRODUCTION}

\section{A. Dealing with the Costs of Energy}

It is obvious that all of the industrial goods or services that help in raising the quality of human life depend on energy. However, as the energy consumption increases, natural resources deplete, environmental pollution rises, and cause the exposure of environmental threats since the production of energy usually depends on the consumption of natural resources. Bunse states that implementing an

\footnotetext{
* Corresponding author: Mustafa Yücel

E-mail: mustafayucel@kastamonu.edu.tr
}

energy management can be a way to decrease energy consumption and prevent the increase of $\mathrm{CO} 2$ emissions [1]. In addition, the effects of greenhouse and other gases and substances should be reduced by increasing energy efficiency in energy production, transmission, distribution, and consumption [2]. So, both the risks of global warming that arose because of the use of fossil fuels and the scarcity of new energy resources caused new implementation in policy instruments [3].

On the other hand, since energy is an input almost in every sector, its necessity grows everyday as a country develops. So, the production of energy is not enough to 
cover the need of energy ideally in many countries. For instance, Turkey imported $\% 15$ of the 80 million tons of coal, $91 \%$ of the 31 million tons of crude oil, $96 \%$ of the 15.1 billion natural gas that was consumed in 2000. Also, the country imported 3 TWh of the total 128 TWh electricity consumption in the same year [4]. To sum up, energy consumption consists one of the main costs, which reaches high amounts, especially in industrial businesses. For example, an industrial plant operating two shifts a day 6 days a week for 50 weeks per year, may require more than one million dollars per year in purchased energy [5].

Briefly stated conditions above caused scholars and business managers to seek better energy management practices. After many experiences and studies, experts from the national standards bodies of 44 ISO member countries participated in the development of ISO 50001, with another 14 countries as observers. The standard also benefitted from the participation of development organizations including United Nations Industrial Development Organization and the World Energy Council [6]. This standard is established on the mutual principles of the previous ISO standards, so it is highly compatible especially with the ISO 9001 and ISO 14001 standards [7].

\section{B. Organization Performance}

While the definition of organization covers both businesses and non-profit organizations in common, it mostly refers to businesses in this article since the energy management was examined for businesses in literature, especially for those which are in an industry sector.

Organizational performance encompasses three specific areas of firm outcomes, which are, financial performance, product market performance, and shareholder return [8]. For more specified explanation, customer satisfaction, employee morale, growth in exports, profitability, overall productivity, reduction in quality costs, overall financial performance, overall operational performance, savings in energy, and environmentally desirable impact of products/services can be considered as the elements of organizational performance [9].

Nevertheless, in order to take the narrowest aspect of business performance, and the dominant model in empirical strategy research, financial performance, which is based on financial indicators that reflect the attainment of economic targets of the organization [10] is used in this article. The most significant dimensions of the financial performance approach are the operating and market performance dimensions [11].
The purpose of this study is to examine and clarify whether the ISO 50001 based energy management systems help the businesses to achieve best organization performance by saving energy without decreasing its output. In the scope of this purpose, applying an integrated energy management system based on ISO 50001 is assumed as more effective than implementing ISO 50001 by merely following its guidance since the organization can measure its performance level more accurately.

\section{RESEARCH METHOD}

The objective of this study is to obtain an overview of the area of energy maturity models, and contributing the literature by proposing a model in a different perspective, which can be integrated to the ISO 50001. Therefore, a systematic literature review of the previous models is conducted according to the Webster [12]. The sources regarding the energy management maturity model published in 2011 and later are selected because of the release date of ISO 50001. In the continuing phases of the research, an empirical study will be held to ensure the usefulness of the model.

\section{LITERATURE REVIEW}

\section{Energy Management and ISO 50001 Standardization}

Lee describes energy management as a process of optimizing energy consumption; and states that it can be done optimally by combining skills of architecture, engineering, management, finance and other skills that are necessary for management functions [13]. Implementing an energy management decreases energy consumption per unit of output by optimizing procedures and systems regarding energy usage [14]. Therefore, energy management helps businesses to maximize their profit by decreasing both the threats that may arise because of the environmental pollution and the direct costs of purchasing or producing energy.

Energy management became popular in recent decades. Before 1970's there were only a few energy-intensive industries, which had been applying energy management, and it was mostly an unheard concept [15]. Nevertheless, according to the data acquired by ISO, there were roughly 7000 companies that had ISO 50001 energy management certificate worldwide in 2014 [16]. This shows that the concept of energy management becomes more vital and 
popular. International Organization for Standardization (ISO) formed an energy management standard, called ISO50001. The standard consists of a set of requirements, which provides a systematic approach to establish, maintain, and improve an energy management system. It helps to achieve continual improvement in energy performance [17]. Pinero states that implementation of an energy management standard like ISO-50001 is expected to increase energy efficiency by more than $20 \%$ in industrial facilities [18].

Furthermore, having ISO-50001 certification can help to increase the market share of an organization as it is based on ISO-14000 environmental management system. Klassen and McLaughlin concluded that marketplace rewarded firms that received awards for investing in areas such as new or redesigned products and processes that minimized their adverse environmental impacts, improved their environmental safety systems, and developed strong management programs in their research [19]. Moreover, British Standards Institution states the expected results of having the certification of ISO-50001 as follows:

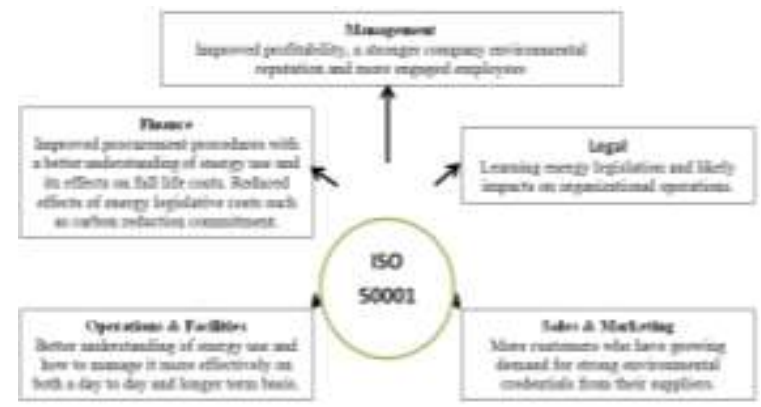

Source: http://goo.gl/R8d7tL

Fig. 1. The benefits of possessing an ISO 50001

As stated in figure 1, having ISO 50001 certificate provides benefits in different aspects. The benefits can be classified into 5 headings, which are management, legal, sales \& marketing, operations \& facilities, and finance. In the management aspect, ISO 50001 helps to improve profit maximization by decreasing costs and expenses to cover energy needs. Also, being certified helps organizations to have a green corporate image. Furthermore, employees may be pleased by working in an organization that is sensitive to environmental issues.

In the legal aspect, the company that implements ISO 50001 management system will know the impacts of current energy legislation. For instance, many governments provide various kinds of incentives to the organizations, which implement ISO 50001 energy management system. Learning about the incentives of government can increase the organization performance dramatically. In addition, if there are certain rules concerning energy usage that the organization doesn't apply, it will discover them before the government, and have the chance of correcting them.

The benefits of ISO 50001 in the sales and marketing certificate on organizational performance area is fulfilling

the demand of customers regarding the environmental issues. The customer may be both the household and

another business organization that has a critical percentage of the organization's products or services. Therefore, implementing an energy management system like ISO 50001 may become one of the most vital steps an organization can take.

ISO 50001 requires an organization to synchronize the operational tasks since any inconsistency in operations may cause waste of energy. Therefore, in the operations and facilities section, ISO 50001 helps to become efficiently organized. Also, facilities will become more suitable for the efficient work of employees.

Finally, in the financial aspect, ISO 50001 can help to improve procurement procedures and principles. By reducing energy usage, and procuring energy efficient equipment, the organization both avoids the threats of environment problems and decreases its monthly energy bills.

The objective of ISO 50001 is providing a framework that helps organizations to develop a policy for more efficient use of energy, set objectives and targets to meet the policy, use data to make decisions regarding energy consumption, measure the results, review the effectiveness, and continually improve energy management [16]. The standardization process of ISO 
50001 aims sustainability and follows the plan-do-check- act (PDCA) cycle of Deming.

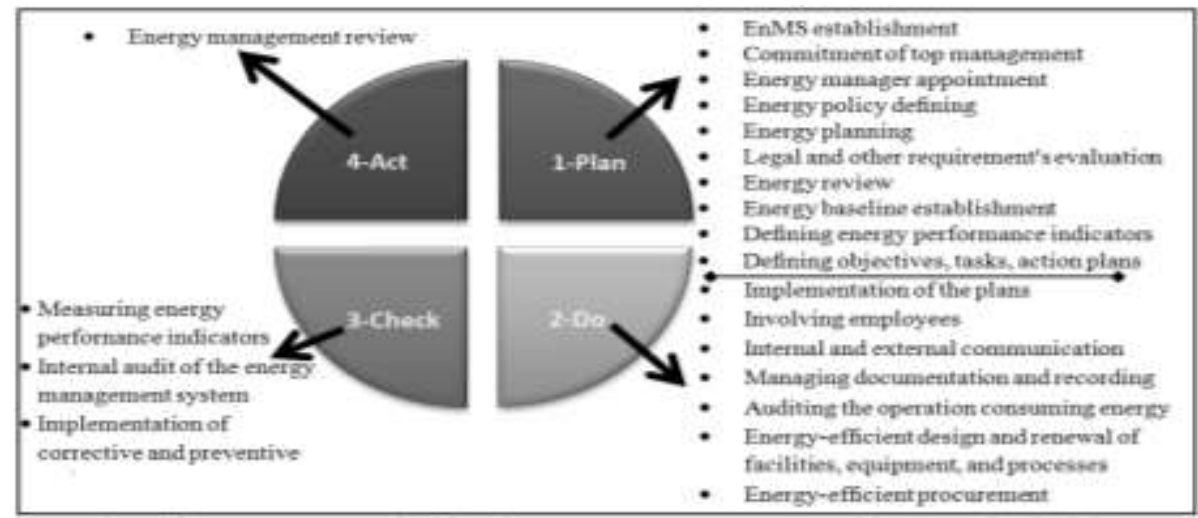

Source: https://goo.gl/CpqBbF

Fig. 2. ISO 50001 Energy management requirements in PDCA cycle

Following the cycle ensures the sustainability of energy policies. As shown in table 1, each phase has requirements and actions to implement energy management. In the planning phase, the commitment of top managers in energy efficiency must be ensured. In this phase, the current situation in energy consumption is examined, the scope of the energy management system is determined, the units that consume significant amount of energy are identified, an energy manager is appointed, required stuff including personnel, tools and equipment are provided to the energy manager, all the legal requirements are clarified, energy performance indicators will be ascertained, targets and action plans are set. In short, every detail that will take part in the energy management implementation should be planned during this period.

After the planning phase, the organization follows up with the "do" phase. This is the step where the planning regarding the energy management is implemented. A crucial point that should always be remembered is that energy management cannot be effective unless all the employees are contended with the procedures since the aim is not just decreasing the energy usage levels, but also keeping the amount of output the same, or increasing it. Hence, all the employees should be involved in the continuous process. Additionally, the energy management applications should be communicated not only with the internal environment, but also with the external environment in order to explain the necessity of the applications and receive complaints, or extra ideas. While implementing the energy management, anything concerning energy management should be recorded. Otherwise, the achievements or costs cannot be clarified properly. Furthermore, the organization may need to purchase, or renovate some tools, equipment, even facilities in order to maintain energy management successfully; of course, after considering the Return On Investment (ROI). Finally, constantly controlling the applications is vital in this phase in order to understand if everything goes on track, and make any adjustment when necessary.

When every aspect of implementation is completed, all of them should be evaluated in the check phase. Energy performance indicators are measured, everything regarding legal aspect is checked and all other managerial issues are audited in this phase. If everything goes well, there is nothing to do more than constantly assessing the mechanism. Otherwise, corrective actions are implemented in this phase. In the act phase, energy management review is conducted. All the problems and solutions are discussed, threats, opportunities, and possible improvements are evaluated in the review, and the new energy policy is formed depending on the conditions.

\section{The Necessity of Integrated Energy Management System}

Although ISO 50001 helped to save millions of dollars in energy, there are many scholars who claim that it is still insufficient and must be improved. The main reason is that ISO 50001 provides requirements and principles to establish a standardized energy management system in order to be able to be suitable for all kind of organizations, so it doesn't provide specific performance measures. While this is an advantage of ISO 50001, it is also a disadvantage that organizations may not be able to set their own performance measures, so cannot understand if they are implementing the energy management optimally or not. 
Therefore, energy management maturity models came into existence.

The usual common feature of energy management maturity models is classifying the maturity of an organization into 5 stages. Jovanovic and Ngai classify stages as initial, managed, defined, quantitatively managed, and optimized to describe energy management levels of an organization based on Capability Maturity Model (CMMI) [20], [21]. O'Sullivan, from Sustainable Energy Authority, categorizes stages as emerging, defining, integrating, optimizing, and innovating by harmonizing with the PDCA cycle [22]. Antunes asserts a maturity model based on PDCA cycle, which divides the stages as initial, planning, implementation, monitoring, and improvement [23]. Introna classified stages as initial, occasional, planning, managerial, and optimal in five different dimensions, which are awareness, knowledge and skills, methodological, energy performances and information systems, organizational structure, and strategy and alignment [15]. All the models stated above try to explain the energy management maturity as promotion level of energy management within the mechanism of an organization including management, employees, contractors etc. On the other hand, in this study, we tried to explain organizational maturity by adding a financial approach to the promotion level of energy management within the framework of PDCA cycle, used by ISO in energy management.

\section{The Proposed Model}

The proposed model consists of 5 stages, associated with 4 phases of PDCA cycle. The 5 stages are basic, transitional, integrated, optimal, and investor. The stages represent the level of success in implementing the energy management in the organization, also, how much the organization is eager to invest in energy management. The model also proposes that as the maturity increases, the amount of investment in energy management increases. Subsequently, analyzing the financial data regarding energy management of an organization may help to understand the maturation level of the organization.

Basic: At the basic stage, there is no significant evidence that the organization is in the interest of energy management. There are only a few individual attempts, but it isn't known in the organizational dimension. There is no measurement of energy consumption, energy policy, objective or task. Also, no investment is made in order to increase energy performance, and the saving is very in return

Transitional: In the transitional stage, the organization recognizes the concept of energy management. A small part of the organization may be more enthusiastic to the energy conservation compared to the other organization members. A small amount of investment may be required in order to employ an energy manager and energy team, and purchase some equipment to measure energy usage in the organization. The objective of the team and the manager is taking the organization to the higher maturity levels. Return on investment may be visible but it is still not enough to claim achievement of energy management.

Integrated: At this stage the concept of energy management is spread out through the organization; everyone accepted the necessity and benefit of energy management, and the majority of the employees participate to increase energy management. However, implementation of energy management is not professional enough. Additional investment may be required at this stage in order to train employees, and renew or purchase of some equipment such as purchasing energy conservative lights. While investments and costs increase, significant rates of energy saving become observable.

Optimal: In this stage, the organization has a unique energy management depending on its necessities and conditions. All the equipment used in the organization including lights, office equipment, and industrial plants is energy conservative, employees are aware of how to prevent waste of energy. More investment may require for renewing bigger machinery, of course as long as the return on investment is applicable. At this stage, the organization may take new business opportunities such as energy consultancy.

Investor: The ISO 50001 energy management standard requires that the energy policy of an organization should address all energy used within the defined scope of the energy management system, which includes electricity, natural gas, steam, solar, and other energy sources [24]. Increasing the usage of renewable energy feasibly requires a more significant amount of investment, but usually, the ROI is applicable. At this stage, the organization has a high commitment to energy conservation and the management is eager to invest large amounts to increase energy performance. Therefore, the organization may go beyond the energy conservation, and start producing energy by using wind turbines, solar plants or other forms of green electricity production, in order to cover its requirements initially, and if possible, to sell the production surplus in the latter. 


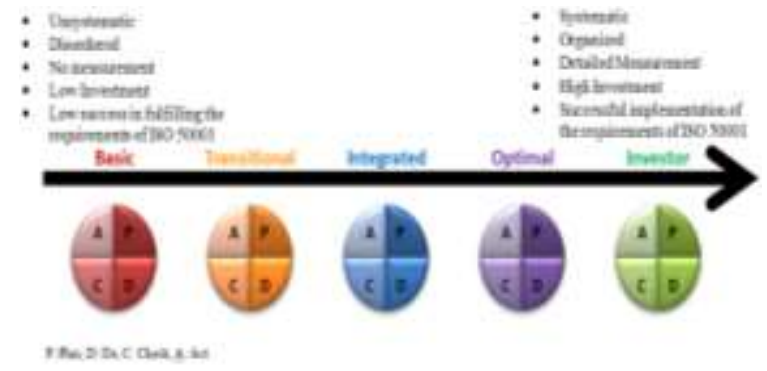

Fig. 3. Energy management maturation progress of an organization

\section{CONCLUSION \& DISCUSSION}

Previous studies that integrate maturation model to an energy management system have shown feedback in a positive way. This is both valid for the companies that have and the ones don't have ISO 50001 certification. This paper presents an integrated energy management system that is formed by adding a maturity model to an ISO 50001 based energy management system. The subject of energy management is relevant and vital under the current conditions of the world. However, there is still a gap in the literature concerning the problems and solutions regarding the energy management in organizations. Therefore, further research must be held in order to fulfill the gap in the industry, for which this study can provide inspiration.

\section{REFERENCES}

[1] K. Bunse, M. Vodicka, P. Schönsleben, M. Brülhart and F. O.Ernst, "Integrating energy efficiency performance in production management-Gap analysis between industrial needs and scientific literature," Journal of Cleaner Production, vol. 19, pp. 667-679, 2011.

[2] K. Bilen, O. Özyurt, K. Bakırcı, S. Karslı, E. M. Yılmaz and O. Çomakll, "Energy production, consumption, and environmental pollution for sustainable development: A case study in Turkey," Renewable and Sustainable Energy Reviews, vol. 12, no. 6, pp. 1529-1561, 2008. DOI: 10.1016/j.rser.2007.03.003

[3] B. Gopalakrishnan, K. Ramamoorthy, E. Crowe, S. Chaudhari and H. Latif, "A structured approach for facilitating the implementation of ISO 50001 standard in the manufacturing sector," Journal of Sustainable Energy Technologies and
This study has particular limitations. First, accomplishing the requirements of planning and implementation of the ISO 50001 system can take approximately 12-13 months before experiencing the sustainability [24]. Therefore, as obtaining solid results can be possible by doing an empirical study, following empirical research regarding this model may take at least one year. Furthermore, only analyzing one organization may not express all the organizations. Different organizations in different regions should be studied. Finally, energy management must be studied deeply in different aspects in organizations such as in management or sales and marketing aspects. Sustaining employee morale or satisfaction of customers are as vital as decreasing costs. Therefore the other aspects should be examined as well in further research.

\section{Assessments, 7, pp. 154-165, 2014. DOI: 10.1016/j.seta.2014.04.006}

[4] Türkiye Bilimsel ve Teknolojik Araştırma Kurumu (TÜBİTAK). (2003, July). Vizyon 2023 enerji ve doğal kaynaklar paneli raporu .[Online]. Available: https://goo.gl/5PhC0o

[5] J. A. Latiner, "An overview of the energy efficiency potential," Environmental Innovation and Societal Transitions, vol. 9, pp. 38-42, 2013. DOI: 10.1016/j.eist.2013.09.005

[6] International Organization for Standardization (ISO). (2011-a, March, 20). Win the energy challenge with ISO 50001. [Online]. Available: http://goo.gl/6lb2WZ

[7] British Standards Institution (BSI). (2011, March, 20). Save money through better energy management with ISO 50001. [Online]. Available: http://goo.gl/h8m8Tw

[8] P. J. Richard, T. M. Devinney, G. S. Yip and G. Johnson, "Measuring organizational performance: Towards 
methodological best practice," Journal of Management, vol.

35, no. 3, pp. 718-804, $2009 . \quad$ DOI: $10.1177 / 0149206308330560$

[9] P. Padma, L. S. Ganesh and C. Rajendran, "A study on the ISO 14000 certification and organizational performance of Indian manufacturing firms," Benchmarking: An International Journal, vol. 15, no. 1, pp. 73-100, 2008.

[10] N. Venkatraman and V. Ramanujam, "Measurement of business performance in strategy research: A comparison of approaches," The Academy of Management Review, vol. 11, no. 4, pp. 801-814, 1986. DOI: $10.2307 / 258398$

[11] J. A. Salvadó, G. M. Castro and J. E. Navas-López, "Green corporate image: Moderating the connection between environmental product innovation and firm performance," Journal of Cleaner Production, vol. 83, no. 15, pp. 356-365, 2014. DOI: $10.1016 /$ j.jclepro.2014.07.059

[12] J. Webster and R. T. Watson,"Analyzing the past to prepare for the future: Writing a literature review," MIS Quarterly, vol. 26, no. 2, pp. 13-23, 2002.

[13] S. K. Lee, M. C. Teng, K. S. Fan, K. H. Yang and R. S. Horng, "Application of an energy management system in combination with FMCS to high energy consuming IT industries of Taiwan," Energy Conversion and Management, vol. 52, no. (8-9), pp. 3060-3070, 2011.

[14] E. A. Abdelaziz, R. Saidur and S. Mekhilef, "A review on energy saving strategies in industrial sector," Renewable and Sustainable Energy Reviews, vol. 15, no. 1, pp. 150-168, 2011. DOI: $10.1016 /$ j.rser.2010.09.003

[15] V. Introna, V. Cesarotti, M. Benedetti, S. Biagiotti and R. Rotunno, "Energy management maturity model: An organizational tool to foster the continuous reduction of energy consumption in companies," Journal of Cleaner Production, vol. 83, no. 15, pp. 108-117, 2014. DOI: 10.1016/j.jclepro.2014.07.001
[16] International Organization for Standardization (ISO). (2016, April, 10). ISO Survey. [Online]. Available: http://goo.gl/Fw3w1b

[17] International Organization for Standardization (ISO). (2011-b, April, 5). ISO 50001:2011 (en) Energy management systemsRequirements with guidance for use. [Online]. Available: https://goo.gl/yqtvA7

[18] E. Piñero. (2009, January, 15). ISO 50001: Setting the standard for industrial energy management. Green Manufacturing News. [Online]. Available: http://goo.gl/Fi9etJ

[19] R. D. Klassen and C. P. McLaughlin, "The impact of environmental management on firm performance," Management Science, vol. 42, no. 8, pp. 1199-1214, 1996. DOI: $10.1287 / \mathrm{mnsc}$.42.8.1199

[20] B. Jovanović and J. Filipović, "ISO 50001 standard-based energy management maturity model-Proposal and validation in industry," Journal of Cleaner Production, vol. 112, no. 4, pp. 2744-2755, 2016. DOI: 10.1016/j.jclepro.2015.10.023

[21] E. W. T. Ngai, D. C. K. Chau, J. K. L. Poon, C. K. M. To, “Energy and utility management maturity model for sustainable manufacturing process," International Journal of Production Economics, vol. 146, no. 2, pp. 453-464, 2013. DOI: 10.1016/j.ijpe.2012.12.018

[22] O'Sullivan, J. (2012). Energy management maturity model (EM3)-A strategy to maximize the potential for energy savings through EnMS. Sustainable Energy Authority of Ireland. [Online]. Available: http://goo.gl/myMHsK

[23] P. Antunes, P. Carreira and M. M. Silva, "Towards an energy management maturity model," Energy Policy, vol. 73, pp. 803-814, 2014. DOI: 10.1016/j.enpol.2014.06.011

[24] M. T. Howell. (2014, March, 20). Effective implementation of an ISO 50001 energy management system (EnMS). [Online]. Available: http://www.ebrary.com

— This article does not have any appendix.- 